\title{
Correction of anomalous origin of left coronary artery using left subclavian artery
}

\author{
J. L. MONRO, G. P. SHARRATT, AND N. CONWAY \\ From the Wessex Regional Cardiac and Thoracic Centre, Southampton
}

$A$ case of anomalous origin of the left coronary artery from the pulmonary artery is reported in which surgical correction by anastomosis of the left subclavian artery to the left coronary artery was performed at the age of 6 months. There was a dramatic clinical improvement, and at 22 months repeat angiocardiography disclosed a patent graft and remarkable improvement in left ventricular function. It is recommended that this is the operation of choice for infants in whom cardiac catheterisation fails to show a shunt into the pulmonary artery or the shunt is small.

Anomalous origin of the left coronary artery from the pulmonary artery is a condition with an 80 per cent mortality in patients having symptoms in infancy (Gasul et al., 1966), but with advances in cardiac surgery definitive correction of this anomaly is now possible. However, there is debate about the best technique. The most commonly performed operation is that of grafting the left coronary artery to the aorta using saphenous vein and this has been done with reasonable success (Cooley et al., 1966; Nora et al., 1968; Somerville and Ross, 1970; Gasior et al., 1971; Akhtar et al., 1973; Endo et al., 1974; Chaitman et al., 1975), but El-Said et al. (1973) reported obliterative changes in 3 of 5 successful grafts.

We report a case in which surgical correction was achieved by anastomosing the left subclavian artery to the left coronary artery, and our experience leads us to believe this to be the procedure of choice for this condition.

\section{Case report}

The patient, a baby girl, presented at the age of 5 months with failure to thrive and tachypnoea. She was the product of a normal pregnancy, and her birthweight was $3.1 \mathrm{~kg}$. There were no neonatal problems but she never fed well and at 5 months of age weighed only $4.5 \mathrm{~kg}$. On examination she was tachypnoeic with subcostal recession. There was moderate hepatomegaly. The peripheral pulses were normal, with no femoral delay. There was an apical lift and a mitral pansystolic murmur with a third sound. The electrocardiogram showed left axis deviation $\left(-30^{\circ}\right)$ and deep $Q$ waves in lead $I$, AVL, V4, V5 and V6, with ST segment elevation. The chest $x$-ray film showed pronounced cardiomegaly. A diagnosis of anomalous origin of the left coronary artery from the pulmonary artery was made. At cardiac catheterisation a left-to-right shunt into the pulmonary artery was not detected; the pulmonary arterial pressure was $30 / 15 \mathrm{mmHg}$ and the indirect left atrial pressure had an $a$ wave of $13 \mathrm{mmHg}$, a $v$ wave of $16 \mathrm{mmHg}$, with a mean pressure of $14 \mathrm{mmHg}$. Aortography confirmed the diagnosis (Fig. 1). Left ventriculography (Fig. 2) showed a very poorly contractile left ventricle (ejection fraction 0.28 ), with moderate mitral regurgitation.

Because of persistent left ventricular failure it was decided to proceed to surgery at the age of 6 months. On 6 March 1975 the left coronary artery was ligated at its origin from the main pulmonary artery. The left subclavian artery was then anastomosed end-to-side to the proximal part of the left anterior descending coronary artery. This was performed without cardiopulmonary bypass. Both of these arteries had a diameter of $2 \mathrm{~mm}$. Left ventricular failure came under control in the next few days and after the postoperative period she did very well, gained weight, and passed her milestones normally. The apical pansystolic murmur was still present and this later became more prominent with a loud third heart sound, which aroused anxiety 


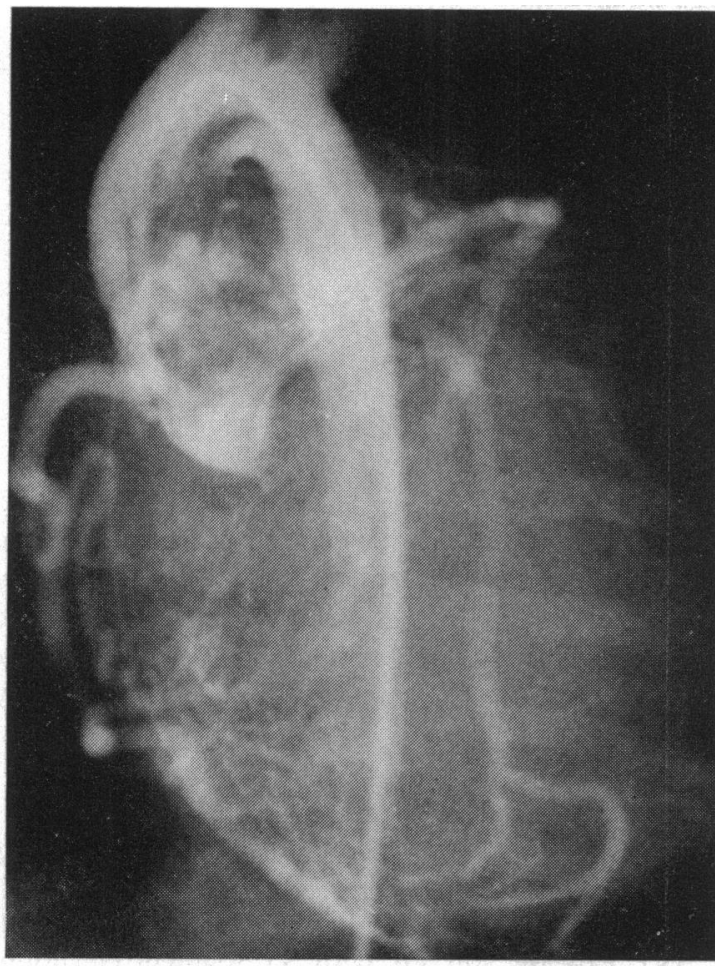

a

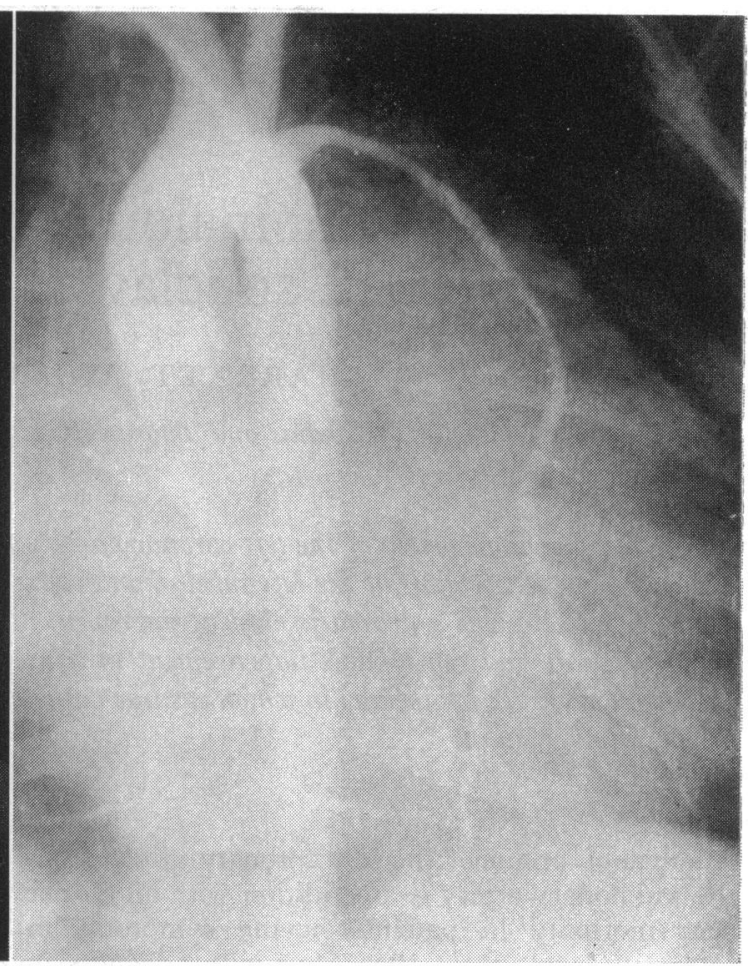

b

Fig. 1 (a) Preoperative aortogram showing the right coronary artery arising from the aorta and filling the left coronary artery retrogradely. (b) Postoperative aortogram showing the left subclavian artery filling the anterior descending branch of the left coronary artery.

about the persistence of left ventricular dysfunction and the patency of the graft. Sixteen months after the operation, at the age of 23 months, cardiac catheterisation was repeated. There was no left-toright shunt. The pulmonary arterial pressure was $15 / 7 \mathrm{mmHg}$, with a $v$ wave of $11 \mathrm{mmHg}$ and a mean pressure of $6.5 \mathrm{mmHg}$ in the wedge tracing. Left ventriculography (Fig. 2) showed severe mitral regurgitation but good left ventricular contraction (ejection fraction 0.77). Aortography (Fig. 1) showed that the left anterior descending coronary artery filled from the left subclavian artery. The circumflex filled from the right coronary artery.

\section{Discussion}

In anomalous origin of the left coronary artery from the pulmonary artery, ligation of the left coronary artery has been the usual practice (Wagner et al., 1967). However, creation of a two-coronary system has the theoretical advantages of a lower risk from ischaemic heart disease should this develop, and in cases with poor intercoronary blood flow, provides an adequate circulation to all parts of the coronary tree.

The operation of saphenous vein grafting has not been reported in infants but it has had considerable success in children in the few cases published. However, El Said et al. (1973) have documented the development of stenosing lesions in these grafts from 2 to 5 years after the operation. Keith (1959) suggested that the use of a systemic arterial anastomosis early in the clinical course should be valuable though Apley et al. (1957) had tried this earlier without success. Wagner et al. (1967) reiterated this view and Meyer et al. (1968) described the first successful operation in a 5-month-old infant. Pinsky et al. (1973) reported 2 further successful operations in an 8-month and a 4-month infant. At follow-up the first had an occluded graft but the second had a patent graft 3 years after operation (Pinsky et al., 1976). Doty et al. (1976) have anastomosed the left subclavian artery to the left coronary artery when this arose from the right pulmonary artery. Patency 


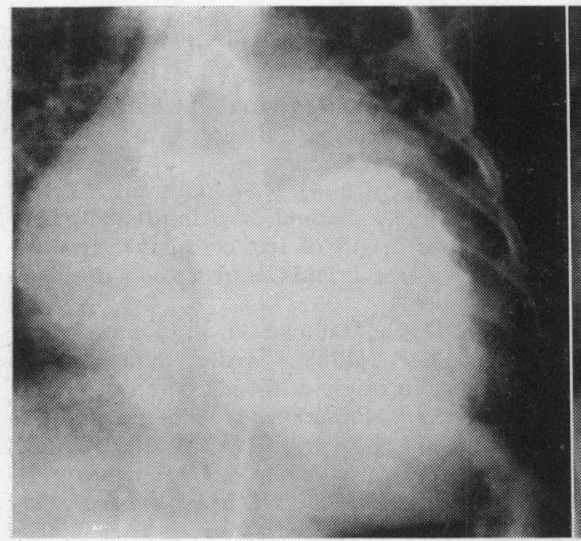

a

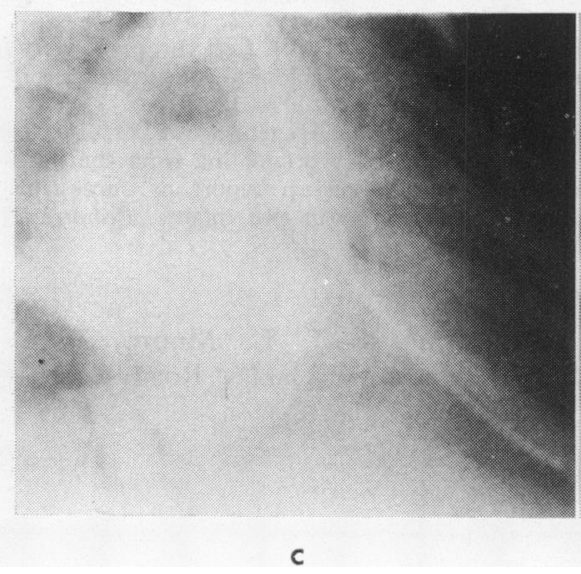

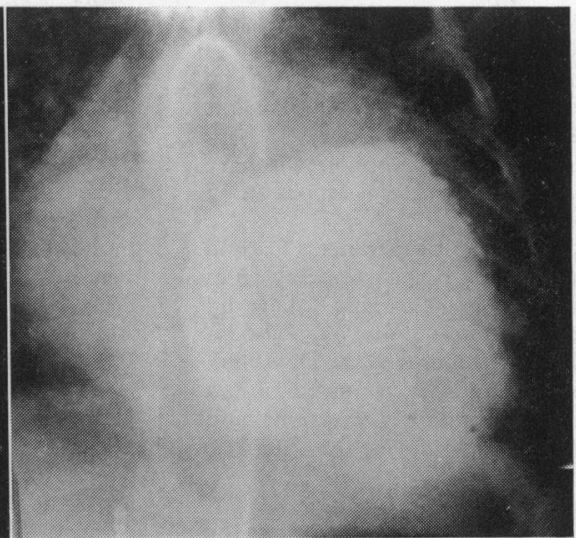

b

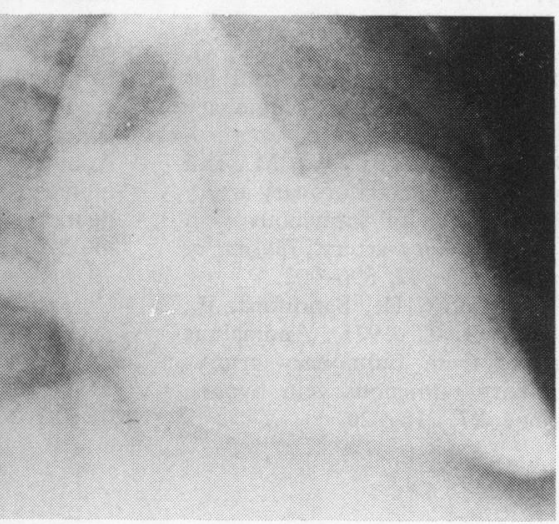

d

Fig. 2 Preoperative left ventriculograms (AP projection) (a) in systole, (b) in diastole.

Postoperative left ventriculograms ( $R A O$ projection) (c) in systole, $(d)$ in diastole. These show severe mitral regurgitation but much improved ventricular contraction.

of the graft was not demonstrated. These cases and our case show that the technique of anastomosing the left subclavian artery to the left coronary artery is feasible in the infant.

It is difficult to be certain of the place of surgery as the small proportion of patients with this anomaly who survive infancy improve spontaneously. Indeed Nora et al. (1968) recommend medical management until childhood before corrective surgery at the age of 5 years. However, by this time many patients will have died and, as a successful surgical alternative appears to be available, it seems reasonable to adopt a more active course. The size of the shunt into the pulmonary artery is important in this decision since Askenazi and Nadas (1975) report that when the shunt is not detectable or very small, there is a high mortality, whereas when there is a large intercoronary flow, survival is the rule. Certainly, our patient, who had no detectable shunt, was in persistent left ventricular failure, and the successful surgical result and dramatic clinical im- provement argue strongly in favour of the active approach, in so far as observations from any single case can. Repeat investigation has shown a patent graft, and a most remarkable improvement in left ventricular function. Mitral regurgitation is still present and severe, but in view of the good left ventricular function and low right heart pressures this should be tolerated for some considerable time.

In conclusion we have confirmed that anastomosis of the left subclavian artery to the left coronary artery is feasible in the infant with anomalous origin of the latter vessel from the pulmonary artery, and believe that it should be performed as soon as possible when there is no detectable shunt into the pulmonary artery or when the shunt is small.

\section{References}

Akhtar, N., Hyland, J. W., and Adam, M. (1973). Anomalous origin of the left coronary artery from the pulmonary artery in an adult: report of a case treated by aorto-coronary 
bypass with the saphenous vein. Fournal of Thoracic and Cardiovascular Surgery, 66, 112-117.

Apley, J., Horton, R. E., and Wilson, M. G. (1957). The possible role of surgery in the treatment of anomalous left coronary artery. Thorax, 12, 28-33.

Askenazi, J., and Nadas, A. S. (1975). Anomalous left coronary artery originating from the pulmonary artery, report on 15 cases. Circulation, 51, 976-987.

Chaitman, B. R., Bourassa, M. G., Lespérance, J., and Grondin, P. (1975). Anomalous left coronary artery from pulmonary artery: an eight year angiographic follow up after saphenous vein bypass graft. Circulation, 51, 552-555.

Cooley, D. A., Hallman, G. L., and Bloodwell, R. D. (1966). Definitive surgical treatment of anomalous origin of left coronary artery from pulmonary artery: indications and results. Fournal of Thoracic and Cardiovascular Surgery, 52, 798-808.

Doty, D. B., Chandramouli, B., Schieken, R. E., Lauer, R. M., and Ehrenhaft, J. L. (1976). Anomalous origin of the left coronary artery from the right pulmonary artery: surgical repair in a 10-month old child. Fournal of Thoracic and Cardiovascular Surgery, 71, 787-791.

El-Said, G. M., Ruzyllo, W., Williams, R. L., Mullins, C. E., Hallman, G. L., Cooley, D. A., and McNamara, D. G. (1973). Early and late result of saphenous vein graft for anomalous origin of left coronary artery from pulmonary artery. Circulation, 47 and 48, Suppl. III, 2-6.

Endo, M., Takayasu, S., Obunai, Y., Nakazawa, M., and Konno, S. (1974). Anomalous origin of left coronary artery from pulmonary artery: significance of saphenous vein bypass between aorta and left coronary artery. Fournal of Thoracic and Cardiovascular Surgery, 67, 896-902.

Gasior, R. M., Winters, W. L., Glick, H., Sandiford, F., Chapman, D. W., and Morris, G. C. (1971). Anomalous origin of left coronary artery from pulmonary artery: treatment by aorto-left coronary saphenous vein bypass. American fournal of Cardiology, 27, 215-220.
Gasul, B. M., Arcilla, R. A., and Lev, M. J. B. (1966). Heart Disease in Children, Diagnosis and Treatment. J. B. Lippincott, Philadelphia.

Keith, J. D. (1959). The anomalous origin of the left coronary artery from the pulmonary artery. British Heart fournal, 21, 149-161.

Meyer, B. W., Stefanik, G., Stiles, Q. R., Lindesmith, G. G., and Jones, J. C. (1968). A method of definitive surgical treatment of anomalous origin of left coronary artery: a case report. Fournal of Thoracic and Cardiovascular Surgery, 56, 104-107.

Nora, J. J., McNamara, D. G., Hallman, G. L., Sommerville, R. J., and Cooley, D. A. (1968). Medical and surgical management of anomalous origin of the left coronary artery from the pulmonary artery. Pediatrics, 42, 405-414.

Pinsky, W. W., Fagan, L. R., Kraeger, R. R., Mudd, J. F. G., and Willman, V. L. (1973). Anomalous left coronary artery; report of two cases. Fournal of Thoracic and Cardiovascular Surgery, 65, 810-814.

Pinsky, W. W., Fagan, L. R., Mudd, J. F. G., and Willman, V. L. (1976). Subclavian-coronary artery anastomosis in infancy for the Bland-White-Garland syndrome. Fournal of Thoracic and Cardiovascular Surgery, 72, 15-20.

Somerville, J., and Ross, D. N. (1970). Left coronary artery from the pulmonary artery; physiological considerations of surgical correction. Thorax, 25, 207-212.

Wagner, H. R., Nadas, A. S., and Hugenholtz, P. G. (1967). Anomalous left coronary artery originating from the pulmonary artery-detailed follow-up report of successful ligation of the aberrant vessel in two infants. Pediatrics, 40, 320-328.

Requests for reprints to J. L. Monro, Esq., F.R.C.S., Western Hospital, Oakley Road, Southampton SO9 4WQ. 